\title{
CHEMISTRY
}

\section{ИК-СПЕКТРОСКОПИЧЕСКОЕ ИССЛЕДОВАНИЕ СТРУКТУРЫ БИОКОМПЛЕКСНЫХ СОЕДИНЕНИЙ МЕТАЛЛОВ С НАКСОДЖИНОМ}

\author{
Цивцивадзе Тенгиз Иванич, доктор химических наук, профессор, \\ Грузинский Технический Университет, Грузия, Тбилиси; \\ Брегадзе Нестан Левановна, докторант Технического университета Грузии, Грузия, Тбилиси; \\ Чигогидзе Нодар Шалвович, доктор химических наук, профессор, \\ Грузинский Технический Университет, Грузия, Тбилиси; \\ Дидбаридзе Изольда Сардионовна, доктор химических наук, профессор, \\ Государственный Университет Ак. Церетели, Грузия, Кутаиси
}

DOI: https://doi.org/10.31435/rsglobal_wos/30112019/6802

\section{ARTICLE INFO}

Received: 10 September 2019

Accepted: 17 November 2019

Published: 30 November 2019

\section{KEYWORDS}

Naxogin (nimorazole), biocomplex compounds

\begin{abstract}
During researching the spectra of biocomplexes of synthesized metals synthesized by us with the organic laxand Naxogin (nimorazole), we compared the spectra of the obtained complexes with the ir-spectra of free (uncoordinated) naxogin (nimorazole). The research showed that the stretching vibration frequencies $v(C=N)$ were $A \sim 10-25 \mathrm{~cm}-1$ in the highfrequency region and rarely in the higher metallicity (but in the acceptable range), which indicates that naxogin is present in these metal complexes (nimorazole). In a coordinated state through one of the two nitrogen atoms of the imidazole cycle. Comparisons were also made with the spectra of noxogenic (nimorazole) metal complexes (manganese, cobalt, nickel, copper, zinc) and other metals chromium(II), iron(II) and iron(III), which convinced us that organic ligands were only centrally connected with the complexes atoms.
\end{abstract}

Citation: Цивцивадзе Тенгиз Иванич, Брегадзе Нестан Левановна, Чигогидзе Нодар Шалвович, Дидбаридзе Изольда Сардионовна. (2019) IR-Spectroscopic Research of the Metal Biocomplex of the Formation of Naxogin. International Academy Journal Web of Scholar. 11(41), Vol.1. doi: 10.31435/rsglobal_wos/30112019/6802

Copyright: (C) 2019 Цивцивадзе Тенгиз Иванич, Брегадзе Нестан Левановна, Чигогидзе Нодар Шалвович, Дидбаридзе Изольда Сардионовна. This is an open-access article distributed under the terms of the Creative Commons Attribution License (CC BY). The use, distribution or reproduction in other forums is permitted, provided the original author(s) or licensor are credited and that the original publication in this journal is cited, in accordance with accepted academic practice. No use, distribution or reproduction is permitted which does not comply with these terms.

Проведено сравнительное изучение ИК-спектров, синтезированных нами биокомплексных соединений металлов с органическим лигандом - наксоджином (ниморазолом) с ИК-спектрами свободного (некоординированного) лиганда - наксоджина. В результате исследования выяснилось, что частоты валентных колебаний $v(C=N)$ смещены на $\sim 10-25 \mathrm{~cm}^{-1}$ в высокочастотную область, хотя реже более сильно (но в допустимых пределах), что свидетельствует о координации наксоджина (ниморазола) в этих металлокомплексах посредством одного из двух атомов азота имидазольного цикла.

Кроме того, проведено сравнение спектров комплексов, синтезированных нами на основе металлов (марганца, кобальта, никеля, меди, цинка), со спектрами комплексов других металлов [Хрома(II), железа(II) и железа(III) с наксоджином], что подтвердило предположение o монодентатной координации органического лиганда с центральным атомомкомплексообразователем только через атом азота имидазольного цикла.

Как было отмечено выше, для изучения способа координации биокоординационных соединений органического лиганда наксоджина (ниморазола) с сульфатами, хлоридами, 
роданидами, формиатами, ацетатами марганца(II), кобальта(II), никеля(II), меди(II), цинка и соответствующей этим соединениям молекулярной структуры мы провели работы по исследованию их ИК-спектров поглощения. С этой целью сняли инфракрасные спектры поглощения (рис.1) свободного (некоординированного) лиганда наксоджина (ниморазола) и выяснили, что его донорные атомы азота имидазольного гетероцикла имеют характерные интенсивные пики поглощения в областях $\sim 1018,1034,1063,1524 \mathrm{~cm}^{-1}$, а карбонил v(CO)-1620$1630 \mathrm{~cm}^{-1}$ и молекулы воды v $\left(\mathrm{H}_{2} \mathrm{O}\right) \sim 3300-3450 \mathrm{~cm}^{-1}$ в соответствующих диапазонах.

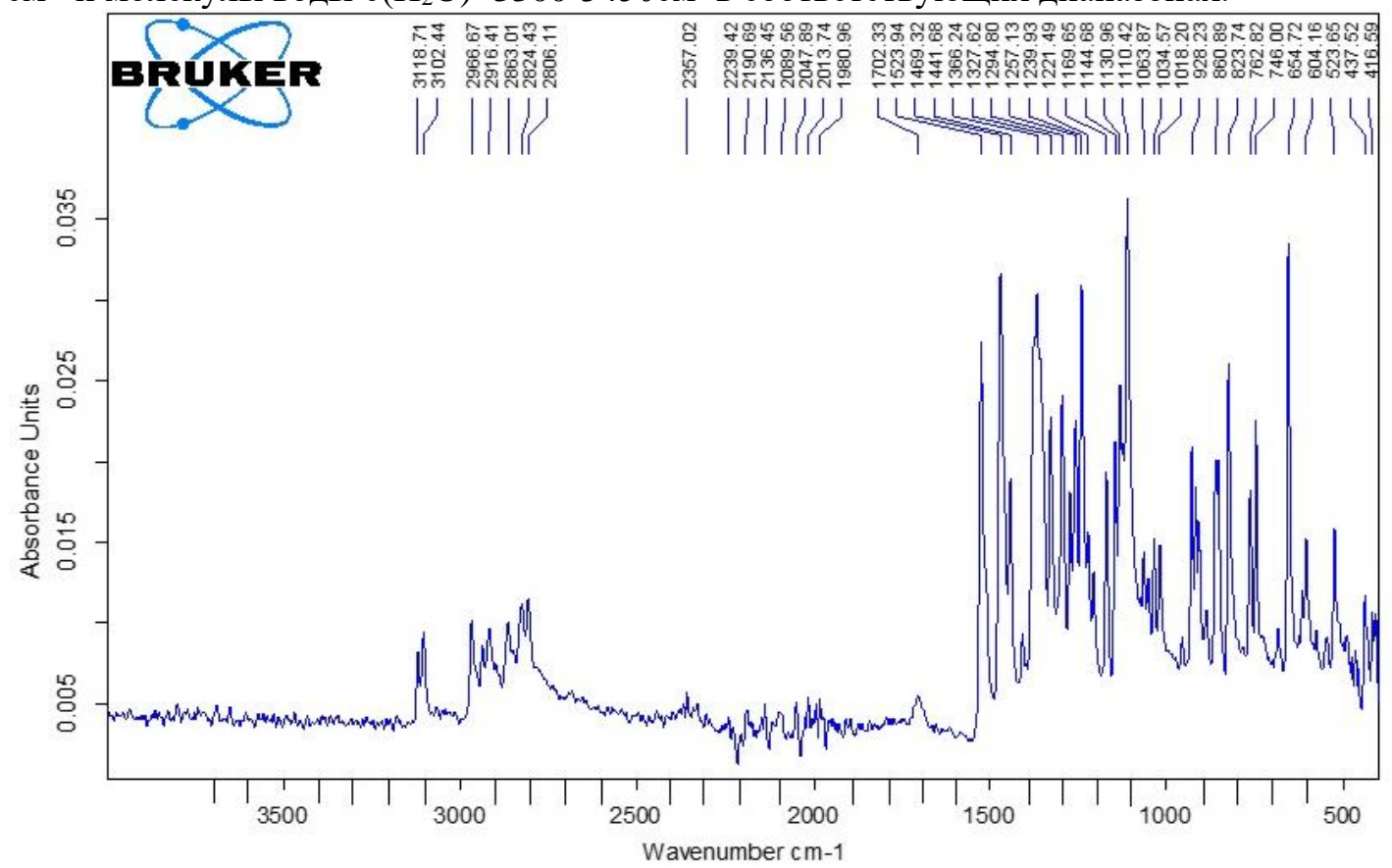

Рис 1. ИК-спектры поглощеения органического лиганда наксоджина $C_{9} H_{14} \mathrm{~N}_{4} \mathrm{O}_{3}\left(500-3500 \mathrm{~cm}^{-1}\right)$

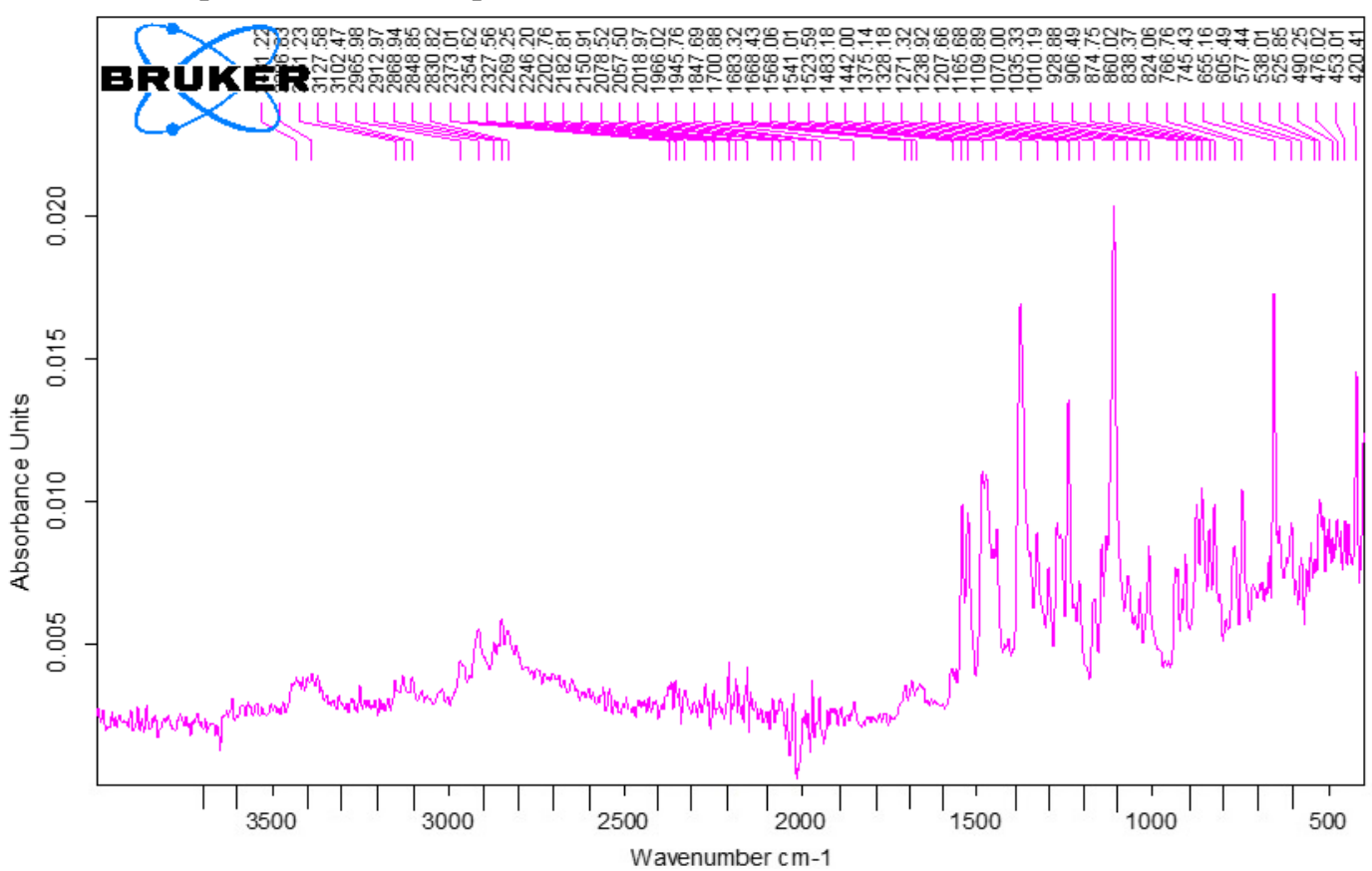

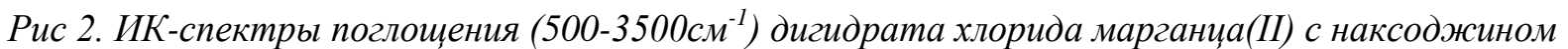
$\left[\mathrm{MnCl}_{2} \cdot\left(\mathrm{C}_{9} \mathrm{H}_{14} \mathrm{~N}_{4} \mathrm{O}_{3}\right)_{2} \cdot\left(\mathrm{H}_{2} \mathrm{O}\right)_{2}\right]$

В комплексе дигидрате хлорида марганца(II) с наксоджином по сравнению со свободным (некоординированным) лигандом у одного атома азота наблюдается смещение частоты колебания в область высокой частоты на 15-20 $\mathrm{cm}^{-1}$ и составляет 1593-1995см-1 (рис.2), которая свидетельствует, что с ионом-комплексообразователем $\mathrm{Mn}^{2+}$ координация молекулы наксоджина осуществляется донорным атомом азота (N4) имидазольного гетероцикла и, 
соответственно, с высокой степенью вероятности имеет место реализация донорноакцепторной связи $\mathrm{Mn} \leftarrow \mathrm{N}=\mathrm{CH}-$. Наксоджин выступает в роли монодентатного лиганда, что полностью соответствует результатам работ других авторов [1-3].

В координационном соединении уменьшение значения частоты колебания $v\left(\mathrm{H}_{2} \mathrm{O}\right)$ молекул воды $\sim 3380 \mathrm{~cm}^{-1}$ указывает на их возможное вхождение во внутреннюю сферу комплекса.

Снижение частоты колебании молекул воды может быть связано также с изменением стереохимии комплексного соединения.

В длинноволновой области ИК-спектров поглощения зафиксированы интенсивные пики 215-238 см с $^{-1}$ что с большой вероятностью указывает на внутрисферное расположение хлоридного ацидолиганда металлокомплексного соединения.

На основании вышеотмеченных ИК-спектроскопических результатов исследований вокруг центрального иона-комплексообразователя марганца(II) реализуется октаэдрическая конфигурация из двух атомов азота гетероцикла монодентатного органического лиганда наксоджина, двух атомов хлора монодентатных ацидолигандов и за счёт двух атомов кислорода двух монодентатных молекул воды.

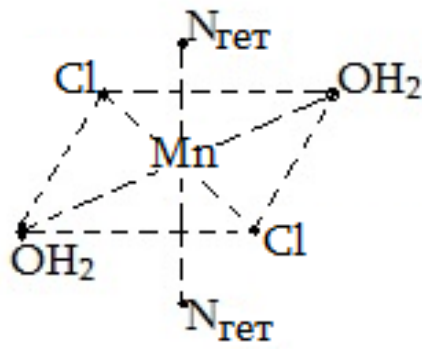

Рис.3. Октаедрическая структура комплексного соединения дигидрата хлорида марганиа(II) с наксоджином $\left[\mathrm{MnCl}_{2} \cdot\left(\mathrm{C}_{9} \mathrm{H}_{14} \mathrm{~N}_{4} \mathrm{O}_{3}\right)_{2} \cdot\left(\mathrm{H}_{2} \mathrm{O}\right)_{2}\right]$

В ИК-спектрах комплекса ацетата никеля((II) с наксоджином $\left[\mathrm{Ni}\left(\mathrm{CH}_{3} \mathrm{COO}\right)_{2} \cdot\left(\mathrm{C}_{9} \mathrm{H}_{14} \mathrm{~N}_{4} \mathrm{O}_{3}\right)_{2} \cdot\left(\mathrm{H}_{2} \mathrm{O}\right)_{2}\right]$ фиксируется частота колебания донорного атома азота гетероцикла в области $\sim 1592 \mathrm{~cm}^{-1}$ (рис.4), что указывает на координацию органического лиганда наксоджина с центральным атомом комплексообразователем ионом $\mathrm{Ni}(\mathrm{II}) \mathrm{Ni} \leftarrow \mathrm{N}_{\text {гет}}$, последнее является очень сильным доказательством того, что органический лиганд наксоджин проявляется в роли монодентатного лиганда (при отсутствии изменения частоты колебания второго атома азота).

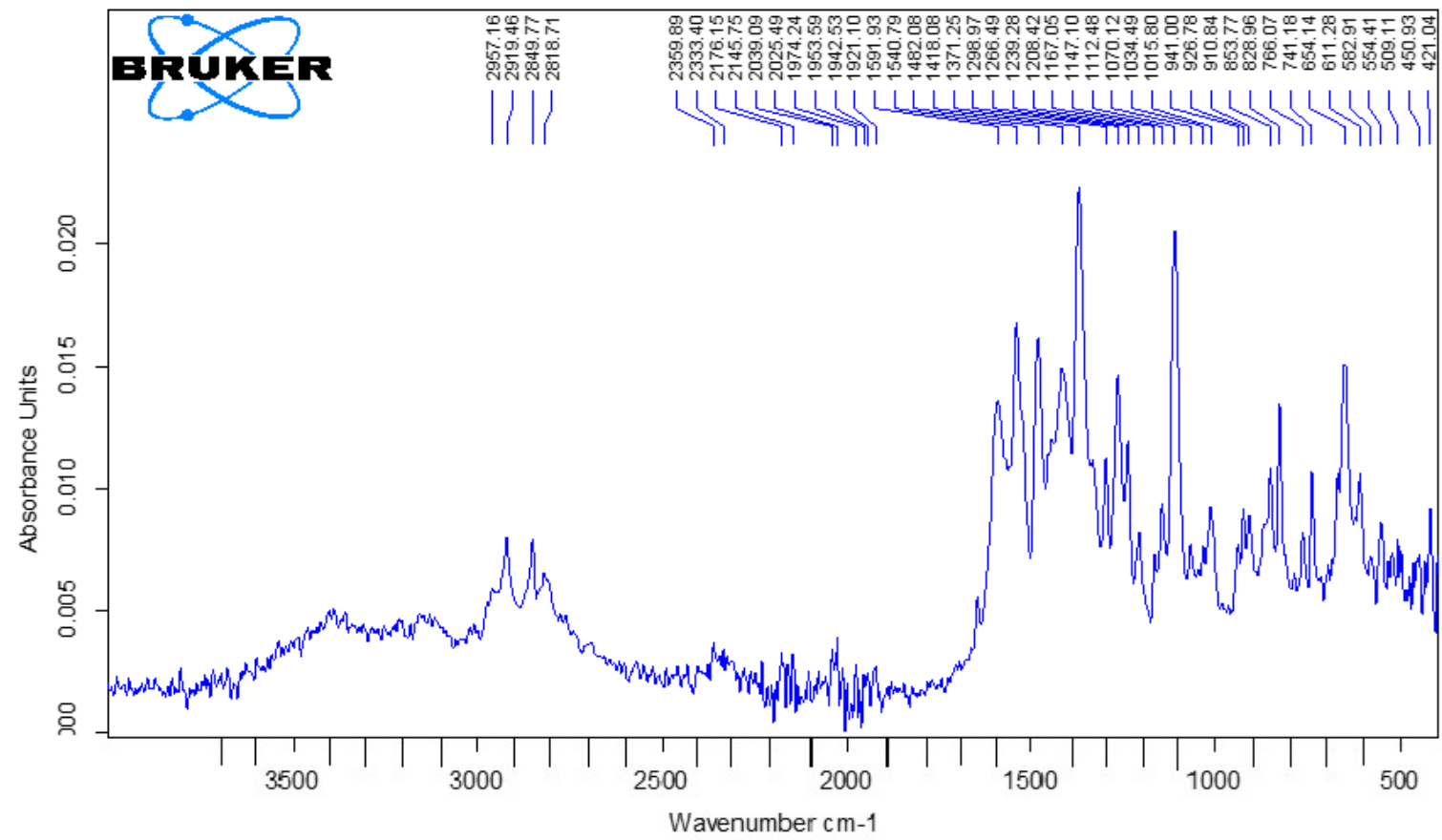

Рис 4. ИК-спектры поглощения (500-3500см-1) комплекса дигидрата ацетата никеля(II) с наксоджсином [ $\left.\mathrm{Ni}\left(\mathrm{CH}_{3} \mathrm{COO}\right)_{2} \cdot\left(\mathrm{C}_{9} \mathrm{H}_{14} \mathrm{~N}_{4} \mathrm{O}_{3}\right)_{2} \cdot\left(\mathrm{H}_{2} \mathrm{O}\right)_{2}\right]$ 
В области ( 3000-3500 $\left.\mathrm{cm}^{-1}\right)$ указанного Ик-спектра поглощения не зафиксированы характерные для молекул воды интенсивные полосы $v\left(\mathrm{H}_{2} \mathrm{O}\right)$, в то же время по результатам химического анализа для данного комплекса никеля((II) с высокой долей вероятности должно быть определённое содержание воды (по нашим многочисленным анализам, расчётам и по источникам научной литературы [1-3] должно быть две молекулы воды). Последнее может быть обусловлено, в основном, внутрисферным расположением молекул воды и, частично, стереохимическими изменениями комплексного соединения.

В исследуемых комплексных соединениях для ацидогрупп соответствующие частоты колебании зафиксированы в длинноволновой области $\sim 421-451 \mathrm{~cm}^{-1}$, которые можно приписать $v(\mathrm{NiO})$. В спектрах ацетатных соединений никеля вышеуказанные полосы поглощения зафиксированы в области $2514-455 \mathrm{~cm}^{-1}$. Отсюда следует, что вокруг иона $\mathrm{Ni}(\mathrm{II})$ реализуется октаэдрическая координация за счёт двух гетероатомов азота, двух атомов кислорода монодентатных ацетатных групп и двух атомов кислорода двух молекул воды $\left[\mathrm{Ni}\left(\mathrm{CH}_{3} \mathrm{COO}\right)_{2} \cdot\left(\mathrm{C}_{9} \mathrm{H}_{14} \mathrm{~N}_{4} \mathrm{O}_{3}\right)_{2} \cdot\left(\mathrm{H}_{2} \mathrm{O}\right)_{2}\right]$.

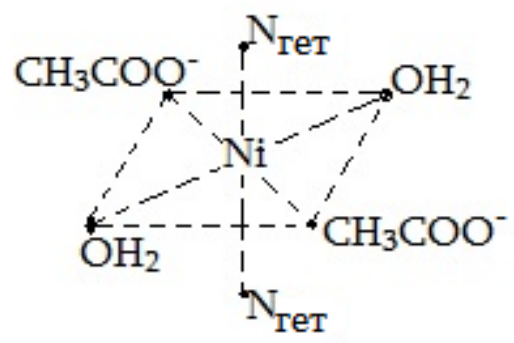

Рис.5. Октаедрическая структура комплексного соединения дигидрата ацетата никеля(II) с наксоджином [ $\left.\mathrm{Ni}\left(\mathrm{CH}_{3} \mathrm{COO}\right)_{2} \cdot\left(\mathrm{C}_{9} \mathrm{H}_{14} \mathrm{~N}_{4} \mathrm{O}_{3}\right)_{2} \cdot\left(\mathrm{H}_{2} \mathrm{O}\right)_{2}\right]$

В молекуле комплексного соединения дигидрата бромида меди(II) с наксоджином $\left[\mathrm{CuBr}_{2} \cdot\left(\mathrm{C}_{9} \mathrm{H}_{14} \mathrm{~N}_{4} \mathrm{O}_{3}\right)_{2} \cdot\left(\mathrm{H}_{2} \mathrm{O}\right)_{2}\right]$ соответствующая частота колебания v( $\left.\mathrm{N}_{\text {гет }}\right)$ донорного азота гетероцикла зафиксирована, как уже было отмечено, в области $\sim 1574 \mathrm{~cm}^{-1}$, которая в синтезированном биокомплексном соединении смещена в высокочастотную область спектра на $\sim 18-20 \mathrm{~cm}^{-1}$ и составляет $\sim 1592 \mathrm{~cm}^{-1}$, что безусловно указывает на монодентатную координацию наксоджина вокруг иона-комплексообразователя меди(II).

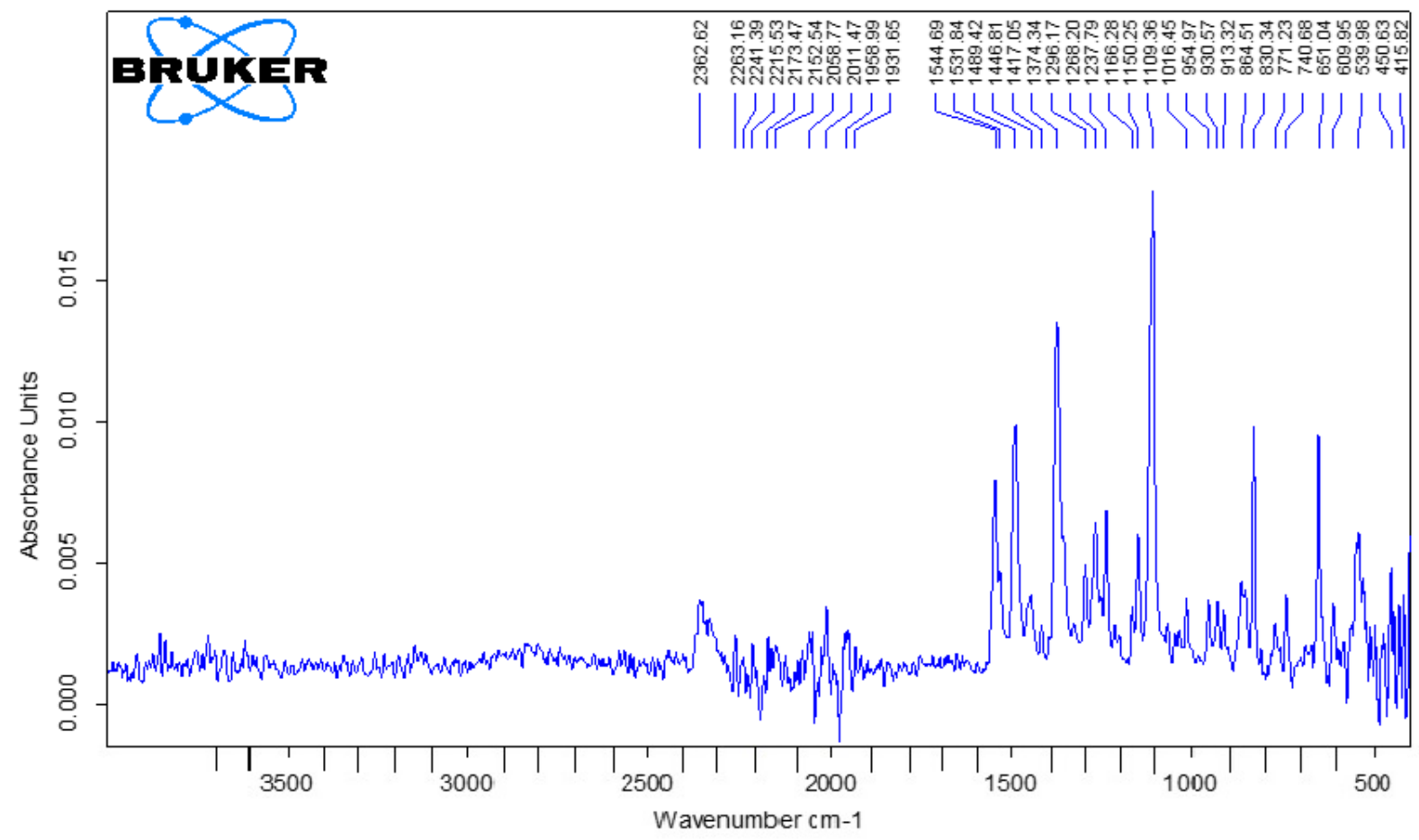

Рис.6. ИК-спектры поглощения (500-3500см $\left.{ }^{-1}\right)$ дигидрата бромида меди(II) с наксоджином $\left[\mathrm{CuBr}_{2} \cdot\left(\mathrm{C}_{9} \mathrm{H}_{14} \mathrm{~N}_{4} \mathrm{O}_{3}\right)_{2} \cdot\left(\mathrm{H}_{2} \mathrm{O}\right)_{2}\right]$ 
Частота колебания второго недонорного атома азота гетероцикла остаётся неизменной и соответствует частоте $~ 1574 \mathrm{~cm}^{-1}$ свободного (некоординированного) атома; это служит доказательством того, что он не участвует непосредственного в координации с ионом меди(II).

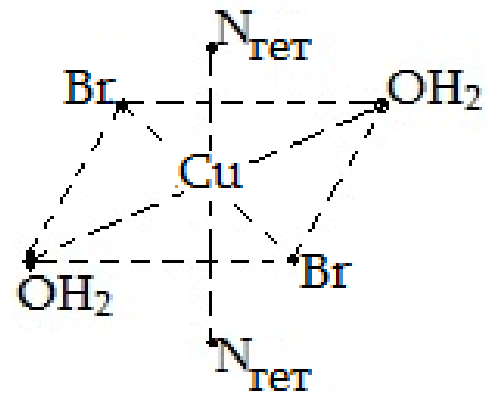

Рис.7. Октаэдрическая структура комплексного соединения дигидрата бромида меди(II) с наксоджином [CuBr $\left.2 \cdot\left(\mathrm{C}_{9} \mathrm{H}_{14} \mathrm{~N}_{4} \mathrm{O}_{3}\right)_{2} \cdot\left(\mathrm{H}_{2} \mathrm{O}\right)_{2}\right]$

В ИК-спектре биокомплесного соединения дигидрата бромида меди(II) с наксоджином снижение на $\sim 30-50 \mathrm{~cm}^{-1}$ значения частоты $v\left(\mathrm{H}_{2} \mathrm{O}\right)\left(\sim 3380 \mathrm{~cm}^{-1}\right)$ указывает на наличие молекул воды во внутренней сфере синтезированного комплекса. Здесь следует отметить, что понижение частоты колебания $v\left(\mathrm{H}_{2} \mathrm{O}\right)$ может указывать на уменьшение числа молекул воды и возможную связь со стереохимическими изменениями в комплексном соединении.

В длинноволновой области ИК-спектров поглощения зафиксированы частоты колебаний в диапазоне 430-465 cм-1, которые с большой вероятностью можно посчитать частотами колебаний атомов брома, непосредственно координированных комплексообразующими ионами меди(II). Ацидолиганды - бромид-ионы выступают в роли монодентатных лигандов.

До начала нашего исследования комплексного соединения дигидрата роданида меди(II) c наксоджином $\left[\mathrm{Cu}(\mathrm{NCS})_{2} \cdot\left(\mathrm{C}_{9} \mathrm{H}_{14} \mathrm{~N}_{4} \mathrm{O}_{3}\right)_{2} \cdot\left(\mathrm{H}_{2} \mathrm{O}\right)_{2}\right]$ было известно, что входящие в металлоокомплексы $\mathrm{NCS}^{-}$- группы могут координировать с металломкомплексообразователем тремя различными способами: атомом азота (M-NCS), атомом серы (M-SCN) и одновременноатомами азота и серы (M-NCS-M)-мостиковая координация.

В последний период, рентгеноструктурными исследованиями [4-6] открыт четвёртый тип координации SCN ${ }^{-}$- груп с кадмием: NCS-M-NCS (одновременная связь атомами азота и серы в условиях монодентатности ацидолиганда). Такая неординарная структура комплексного соединения кадмия обусловлена его особенного высокой биоактивностью (корреляция между структурой и биоактивностью).

В нашем конкретном случае частота валентных колебаний v(CN) $\mathrm{NCS}^{-}$-групп в случаях комплексных соединений кобальта и марганца проявляется в области $2050 \mathrm{~cm}^{-1}$, а в случае ИКспектров поглощения комплекса никеля проявляется в областях $2065 \mathrm{~cm}^{-1}, 2105 \mathrm{~cm}^{-1}$ и $2140 \mathrm{~cm}^{-1}$.

В биокоординационном соединении роданида меди(II) c наксоджином $\left[\mathrm{Cu}(\mathrm{NCS})_{2} \cdot\left(\mathrm{C}_{9} \mathrm{H}_{14} \mathrm{~N}_{4} \mathrm{O}_{3}\right)_{2} \cdot\left(\mathrm{H}_{2} \mathrm{O}\right)_{2}\right]$ в ИК-спектрах поглощения в области 2050 см$^{-1}$ обнаружена достаточно интенсивнвя полоса поглощения, которая возможно принадлежит частоте валентных колебаний $v(\mathrm{CN})$, что с высокой степенью вероятности указывает, что роданидная $\mathrm{SCN}^{-}$- группа непосредственно связана с ионом-комплексообразователем меди(II) $v(\mathrm{Cu} \leftarrow \mathrm{NCS})$ [4,5]. В ИК-спектрах поглощения этого же комплексного соединения фиксируется интенсивная полоса в области $1633 \mathrm{~cm}^{-1-}$, что указывает на координацию молекулы наксоджина с ионом меди(II) через атом азота гетероцикла $\left(\mathrm{Cu} \leftarrow \mathrm{N}_{\text {гет. }}\right)$ (Рис.8).

В высокочастотной области ИК-спектра данного комплекса проявляет себя сравнительно слабой интенсивности полосы поглощения $3114 \mathrm{~cm}^{-1}$ и $3400 \mathrm{~cm}^{-1}$, которые с высокой вероятностью можно отнести к v $\left(\mathrm{H}_{2} \mathrm{O}\right)$ молекул воды, что доказывает их наличие. 


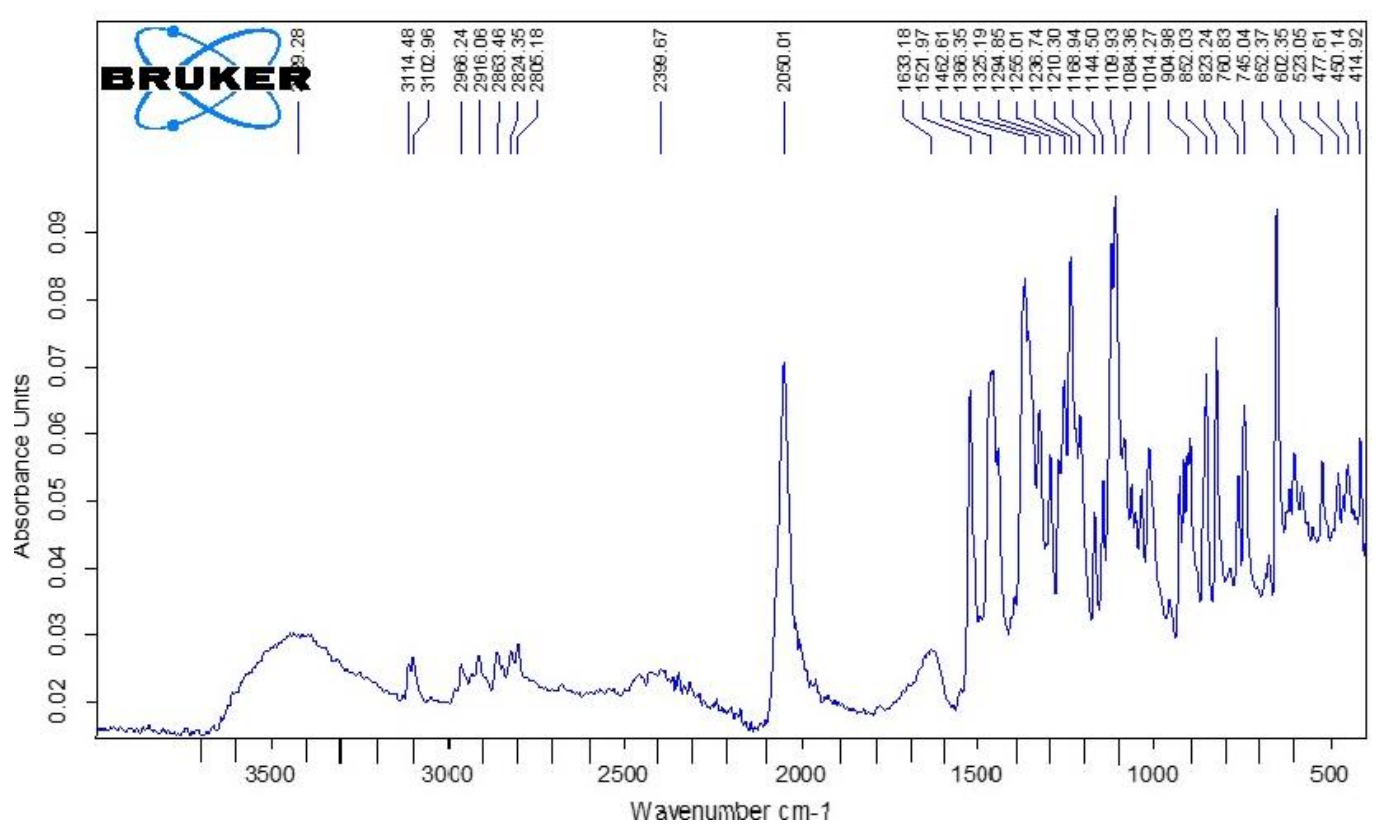

Рис.8. ИК-спектры поглощения комплексного соединения дигидрага роданида меди(II) с наксоджином $\left[\mathrm{Cu}(\mathrm{NCS})_{2} \cdot\left(\mathrm{C}_{9} \mathrm{H}_{14} \mathrm{~N}_{4} \mathrm{O}_{3}\right)_{2} \cdot\left(\mathrm{H}_{2} \mathrm{O}\right)_{2}\right]$

В целом вокруг иона меди(II) осуществляется октаэдрическая координация двумя атомами азота гетероцикла монодентатного наксоджина, двумя атомами азота двух изотиоцианатных групп и двумя атомами кислорода двух молекул воды (Рис.9).

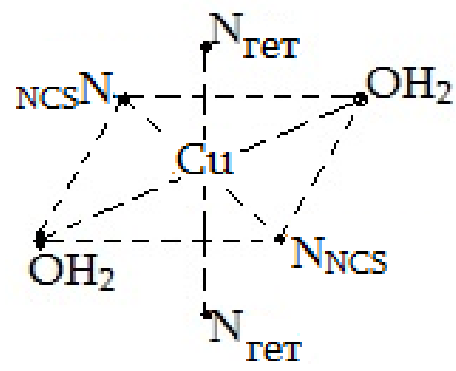

Рис.9. Октаэдрическая структура комплексного соединения дигидрага роданида меди(II) с наксоджином $\left[\mathrm{Cu}(\mathrm{NCS})_{2} \cdot\left(\mathrm{C}_{9} \mathrm{H}_{14} \mathrm{~N}_{4} \mathrm{O}_{3}\right) \cdot\left(\mathrm{H}_{2} \mathrm{O}\right)_{2}\right]$

В результате ИК-спектроскопического исследования структуры комплексного соединения дигидрата роданида цинка с наксоджином $\left[\mathrm{Zn}(\mathrm{NCS})_{2} \cdot\left(\mathrm{C}_{9} \mathrm{H}_{14} \mathrm{~N}_{4} \mathrm{O}_{3}\right)_{2} \cdot\left(\mathrm{H}_{2} \mathrm{O}\right)_{2}\right]$, наличие интенсивной полосы в области $\sim 1625 \mathrm{~cm}^{-1}$ можно отнести к донорному атому азота гетероцикла или к атому кислорода корбонильной (CO)-группы, с помощью которых органический лиганд наксоджин $\left(\mathrm{C}_{9} \mathrm{H}_{14} \mathrm{~N}_{4} \mathrm{O}_{3}\right)$, с большой вероятностью, координирует с комплексообразующим

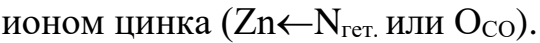

На данном этапе исследований с большой вероятностью можно сказать, что атом кислорода карбонильной (СО)-группы молекулы наксоджина не участвует в координации с комплексообразующим ионом цинка - соответствующие частоты имеющихся полос поглощения v(CO) ИК-спектров комплексного соединения не смещаются в низкочастотную область в сравнении с частотами исходного лиганда.

В ИК-спектрах данного комплексного соединения в высокочастотной области 3370$3400 \mathrm{~cm}^{-1}$ зафиксирована достаточно большого объёма интенсивная полоса, которую можно представить как частоту колебания молекул воды, которые непосредственно координированы с центральным комплексообразующим ионом цинка $\left(\mathrm{Zn} \leftarrow \mathrm{OH}_{2}\right)$, с расположением во внутренней координационной сфере синтезированного комплексного соединения (Рис.10).

В ИК-спектре этого комплекса цинка валентная частота колебания v(CN) NCS- -группы составляет приблизительно $2050 \mathrm{~cm}^{-1}$, что с большой вероятностью доказывает, что роданидные $\mathrm{NCS}^{-}$- группы монодентатные - координированы с ионом цинка атомами азота, расположены во внутренней координационной сфере и реализована изотиоцианатная 
$\left(\mathrm{Zn} \leftarrow \mathrm{N}_{\mathrm{NCS}}\right)$ структура. Это утверждение усиливает то, что в ИК-спектрах комплексного соединения зафиксированы низкочастотные и низкой интенсивности полосы поглощения $\sim 780 \mathrm{~cm}^{-1}$, которые можно отнести к частоте $v(\mathrm{CS})$ изотиоцианатной группы.

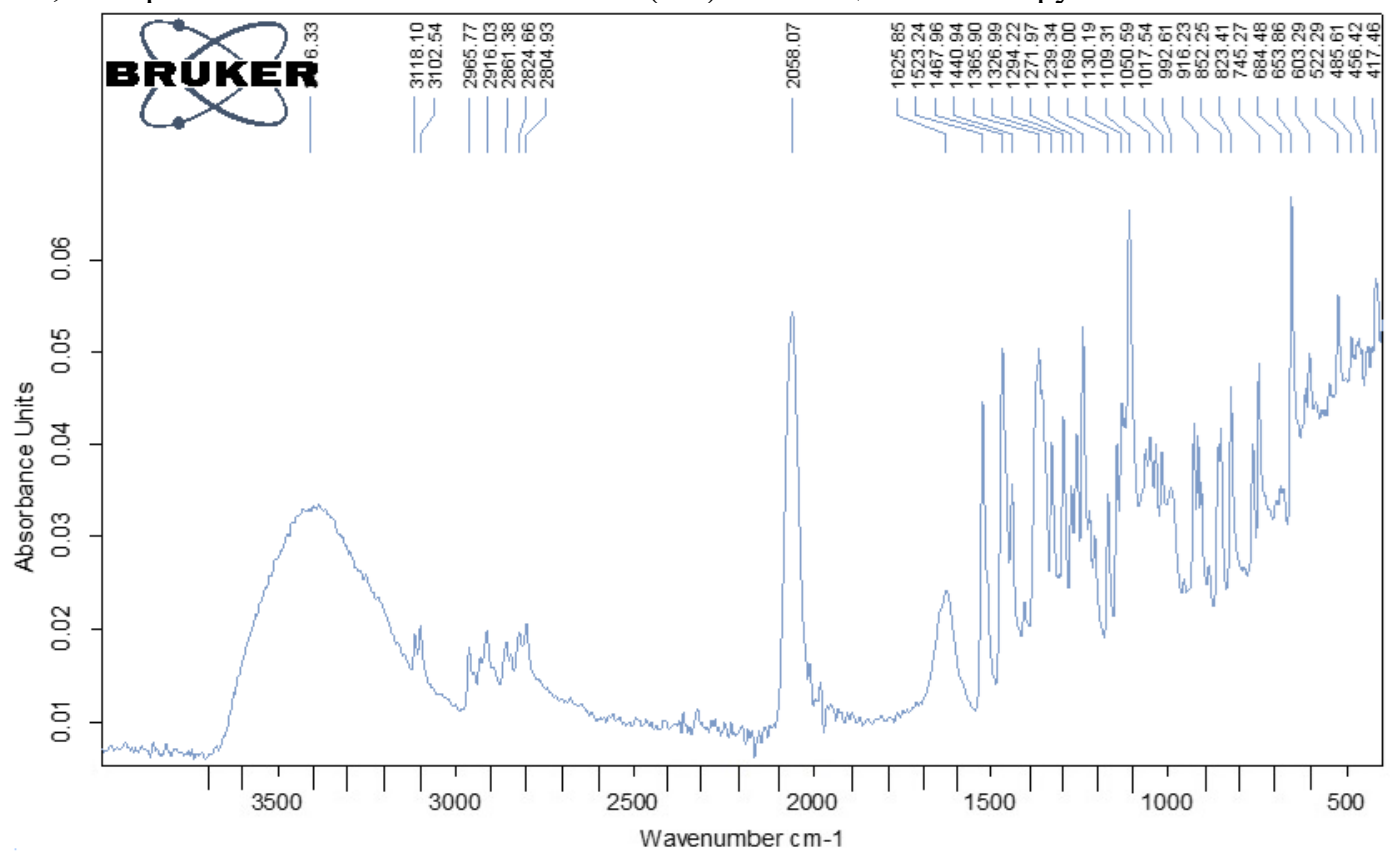

Рис. 10. ИК-спектры поглощения комплексного соединения дигидрата роданида иинка с наксоджином $\left[\mathrm{Zn}(\mathrm{NCS})_{2} \cdot\left(\mathrm{C}_{9} \mathrm{H}_{14} \mathrm{~N}_{4} \mathrm{O}_{3}\right)_{2} \cdot\left(\mathrm{H}_{2} \mathrm{O}\right)_{2}\right]$

На основании анализа вышеуказанных данных, с большой вероятностью, можно сделать заключение, что комплексное соединение роданида цинка с наксоджином имеет октаэдрическую структуру - из двух атомов азота гетероцикла двух молекул наксоджина (или из двух атомов кислорода двух карбонильных групп), из двух атомов азота изотиоцианатных групп и двух атомов кислорода двух молекул воды (Рис. 11).

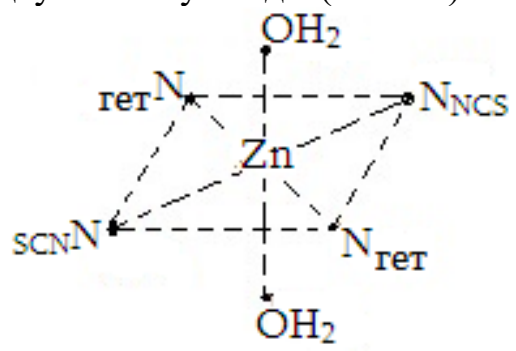

Рис.11. Октаэдрическая структура комплексного соединения дигидрага роданида иинка(II) с наксоджсином $\left[\mathrm{Zn}(\mathrm{NCS})_{2} \cdot\left(\mathrm{C}_{9} \mathrm{H}_{14} \mathrm{~N}_{4} \mathrm{O}_{3}\right)_{2} \cdot\left(\mathrm{H}_{2} \mathrm{O}\right)_{2}\right]$

\section{ЛИТЕРАТУРА}

1. Soledad Betanzoz - Lara, Celedonio Gowez -Ruiz, Lidia R., Barron - Sosar, Isabel Gracia, Marcos Flores - Alamo, Norah Barba -Behrens. Journal of inorganic Biochemistry 114. „Cytoxic copper(II), Cobalt(II) and Nikel(II) coordination conpounds of clotrimazole“ Pg. 82-93. 2010

2. Джафаридзе Р. Комплексные соединения некоторых биометаллов с противогрибковым препаратом - клотримазолом. Автореферат диссертации. Тбилиси, 2016.

3. Гвердцители Л., Цинцадзе Г., Цивадзе А. Координационные соединения карбоксилатов некоторых металов с амидами пиридинкарбоновых кислот и их биологические свойства. „Технический университет“, Тбилиси, 2017.

4. Гонгадзе Н. П. Исследование координационных соединений металов с N,N-диетилникотинамидов и амидом никотиновой кислоты. Канд. Дис., Тбилиси, 1976.

5. Цивадзе А. Ю. Спектрохимия амидокомплексов металлов. Диссертация на соискание учёной степени докдора химических наук. Москва, 1978.

6. Цинцадзе Г.В., Цивцивадзе Т. И., Квиташвили А. И., Туриашвили Т. Н. Кристалическая и молекулярная структура тиоцианатоизотиоцианатодибензоилгидразида кадмия. Доклады Ан СССР. T. 260. №5. стр. 1136-1139. 1981. 